\title{
Uma introdução ao estudo da Companhia Estrada de Ferro Melho- ramentos do Brasil
}

\author{
An introduction to the study Company Railroad Melhoramentos do Brasil
}

Ana Beatriz Pacheco Lima Vaz ${ }^{1}$, Magno Fonseca Borges².

\begin{abstract}
Resumo
\author{
Neste trabalho buscamos apresentar algumar reflexões preliminares sobre a Estrada de Ferro Melhoramentos do Brasil e \\ sua relação com o desenvolvimento de Governador Portela. \\ Palavras-Chave: Estrada de Ferro Melhoramentos do Brasil. Governador Portela. Serra do Tinguá.
}

Como citar esse artigo. Vaz ABPL, Borges MF. Uma introdução ao estudo da Companhia Estrada de Ferro Melhoramentos do Brasil. Revista Mosaico. 2015 Jul./Dez.; 06 (2): 49-58.

\begin{abstract}
In this work we present some preliminary reflections on the Company Railroad Melhoramentos do Brasil and its relation to the development of Portela Governor.

Keywords: Company Railroad Melhoramentos do Brasil. Governador Portela. Serra do Tinguá.
\end{abstract}

\section{Introdução}

O século XIX foi marcado por muitas transformações econômicas, políticas e sociais. Entre estas mudanças, ocupou papel de destaque a construção das primeiras malhas ferroviárias. Considerado como um dos maiores símbolos de modernidade, naquele instante, as estradas de ferro multiplicaram-se em todo o ocidente.

Segundo o pesquisador Hélio Suêvo Rodriguez, foi ao longo do século XIX que se deu a formação do conhecimento técnico-científico necessário à transformação do vapor em força motora capaz de tracionar as locomotivas sobre trilhos. Tratou-se de uma longa trajetória a construção deste ramo do saber e sua aplicação junto à sociedade. As primeiras ferrovias foram construídas na Inglaterra e, quase ao mesmo tempo, nas Américas. Na América do Norte e na América Central, foi nos Estados Unidos e em Cuba que se deu a implantação das primeiras ferrovias americanas ainda na década de $1830 .^{1}$

Naquele momento, apesar da grande repercussão causada pela notícia do desenvolvimento ferroviário, sua implantação, em escala mundial, se dava de modo

1 Cf. RODRIGUES, Hélio Suêvo. A formação das estradas de ferro no Rio de Janeiro: o resgate da sua memória. Memória do Trem, 2004, páginas 12-14. bastante tímido. A década de 1850 representou uma virada neste cenário. As ferrovias foram multiplicadas. Em vários locais, como na França, na Bélgica, na Espanha e no Egito, por exemplo, os debates sobre a questão ferroviária foram intensos. Na América do Sul, a primeira ferrovia foi construída na Guiana Inglesa, em 1848. Era uma estrada bastante curta. Possuía apenas 8 km de extensão. Em 1851 foi inaugurada uma pequena ferrovia no Peru e em 1852 no Chile. ${ }^{2}$

O Brasil não esteve fora deste contexto. A sua primeira linha ferroviária foi inaugurada em 1854. Tratava-se do empenho realizado por Irineu Evangelista de Souza. O interesse na questão ferroviária no Brasil era tão grande que, por conta deste feito, seu principal articulador recebeu o título de Barão de Mauá.

Ainda naquele mesmo instante foi iniciada a construção de uma nova ferrovia na província do Rio de Janeiro. Tratava-se da Estrada de Ferro D. Pedro II. O principal desafio da fase inicial desta construção era a definição do traçado mais apropriado para que a estrada de ferro ultrapassasse a Serra do Mar. Após muitos debates, definiu-se que o modo mais apropriado seria levar os trilhos de Belém (atual município de Japeri), até o local conhecido à época como Rodeio (atual município de Engenheiro Paulo de Frontin). De lá, os

2 Idem, página 14

1. Graduanda em História pela Universidade Severino Sombra (USS).

2. Doutorando em História no Programa de Pós-Graduação em História da UNIRIO (bolsista CAPES) e docente dos cursos de História, Pedagogia, Farmácia e Medicina da USS. 
trilhos chegariam ao local de encontro do Rio Piraí com o Rio Paraíba do Sul (atual município de Barra do Piraí).

Havia outra proposta que ganhou força a época, mas que não foi a escolhida. Também partindo do povoado de Belém, os trilhos seguiriam em direção a Serra do Tinguá, em paralelo ao Rio Santana. Atingiriam o povoado de Morro Azul e de lá, até a Vila (depois cidade) de Vassouras.

Em 1858 foi iniciada a construção do trecho da Estrada de Ferro que ultrapassou a Serra do Mar, a partir do traçado Belém - Rodeio - Barra do Piraí. Segundo o pesquisador Pedro Marinho, ${ }^{3}$ a Estrada de Ferro D. Pedro II foi o grande laboratório para o desenvolvimento da Engenharia Imperial. Para ele, a participação dos engenheiros brasileiros nos postos de direção desta ferrovia (principalmente a partir de 1865) favoreceu o desenvolvimento do konw how necessário ao momento máximo de expansão ferroviária no Brasil, que atravessou o Império e adentrou a República.

Ainda durante o período Imperial, os debates sobre a construção de uma nova linha ferroviária que levasse os trilhos ao interior da Serra do Tinguá foram retomados. ${ }^{4}$ Porem, foi exatamente no início da República que esta proposta foi posta em movimento. Em 1890 foi criada a Companhia Estrada de Ferro Melhoramentos do Brasil. Em sua administração estava o Engenheiro André Gustavo Paulo de Frontin.

Nosso trabalho de pesquisa parte deste ponto. A chamada Linha Auxiliar, construída pela Companhia Estrada de Ferro Melhoramentos do Brasil, sob a direção do Engenheiro Paulo de Frontin, teve importantes desdobramentos de ordem política, econômica e social para a região por ela percorrida. Foi por conta desta estrada, que se formou o Distrito de Governador Portela. E é sobre a relação entre este distrito e a linha férrea que desenvolvemos nosso estudo.

\section{Estrada de Ferro Melhoramentos do Brasil}

Quando aconteceu o golpe que derrubou o sistema monárquico no Brasil, o tenente-coronel Francisco Victor da Fonseca e Silva foi nomeado para comandar o corpo policial do Rio de Janeiro. A principal tarefa que recebeu de Deodoro da Fonseca, naquele dia 15 de novembro de 1889, foi tomar o comando da Província do Rio de Janeiro. Naquele mesmo dia, derrubou do governo o então presidente provincial Carlos Afonso de Assis Figueiredo (que era um ferrenho apoiador do regime monárquico) e assumiu interinamente o governo

3 MARINHO, Pedro Eduardo Mesquita de Monteiro. Companhia Estrada de Ferro D. Pedro II: a grande escola prática da nascente Engenharia Civil no Brasil oitocentista.Topoi (Rio de Janeiro), v. 16, n. 30, 2015. p. 203-233.

V. 16, n. 30, 2015. p. 203-233.

conquistas: do século XVII ao século XX. Volume IV - Pelos Trilhos do tempo. Dedalus $1^{a}$ ed.: Rio de Janeiro, 2003. Página 25. do Estado do Rio de Janeiro.

No dia seguinte, Deodoro da Fonseca - a frente do Governo Provisório da República Brasileira - anunciou a nomeação de Francisco Portela como novo presidente do Estado do Rio de Janeiro. Francisco Portela governou, como presidente provisório entre 16 de novembro de 1889 e 11 de maio de 1891, quando foi eleito por voto indireto como o primeiro Presidente Constitucional do Estado. Nesta condição, governou até 10 de dezembro de 1891.

O ano de 1891 foi marcado por grande turbulência política. Em 23 de novembro Deodoro da Fonseca foi forçado a renunciar. Neste momento Floriano Peixoto assumiu o governo e deu início a um grande conjunto de mudanças administrativas. Entre elas, a substituição dos presidentes dos Estados. Foi no bojo destas mudanças que Francisco Portela deixou a presidência do Estado do Rio de Janeiro, sendo substituído, interinamente por José Marques Guimarães, que permaneceu na função por apenas um dia, sendo substituído por Carlos Baltasar da Silveira.

Baltasar da Silveira assumiu a presidência do Estado, a convite de Floriano Peixoto, até que fossem realizadas novas eleições. Em 3 de maio de 1892 foi substituído por José Porciúncula, que venceu as eleições como candidato do Partido Republicano Fluminense.

Desde a década de 1850 , o modelo civilizatório adotado pelos dirigentes imperiais incluíam as obras de infraestrutura, chamadas a época de melhorias materiais. ${ }^{5}$ Entre estas obras, o maior destaque coube aos esforços para irradiar as malhas ferroviárias em diversas partes do Brasil. As construções das estradas de ferro estiveram presentes tanto no momento da máxima expansão do Estado Imperial, por volta da década de 1860 , como também estiveram presentes no momento da abertura da crise imperial no início da década de 1870 e mesmo no instante mais agudo desta crise, ao longo da década de 1880. Segundo o professor Sebastião Deister, a retomada dos debates em torno da abertura de uma linha férrea que atingisse a região da Serra do Tinguá se deu em 1882, a partir de um contrato firmado entre a Província do Rio de Janeiro e os engenheiros Eduardo Hargreaves, Luiz Rafael Vieira Souto e Conrado Niemeyer. ${ }^{6}$

Contudo, o projeto não saiu das intenções. Foi exatamente durante o governo de Francisco Portela que a ideia foi desengavetada e iniciou-se um conjunto de articulações políticas para que fosse levada a cabo. Francisco Portela esteve à frente de um conjunto de ações que buscavam retomar o projeto Ferroviário Fluminense como estratégia de modernização da sociedade e dinamização da economia do Estado. Foi por sua iniciativa que em 1890 se constituiu o primeiro município criado na República. Trata-se de Barra do

\footnotetext{
5 MARINHO, Pedro Eduardo Mesquita de Monteiro. Companhia Estrada de Ferro D. Pedro II: a grande escola ... Op. Cit. página 208 grande escola ... Op. Cit. página 208.
6 DEISTER, S. Pelos Trilhos do tempo... página 25.
} 
Piraí, que naquela época continha o maior entroncamento férreo de toda a América Latina. Foi em seu governo que a ideia de ampliar a malha ferroviária fluminense foi posta em movimento.

Ao desengavetar a proposta de levar os trilhos através da Serra do Tinguá, Francisco Portela estimulou a formação da Companhia Estrada de Ferro Melhoramentos do Brasil, criada em 17 de maio de 1890. ${ }^{7} \mathrm{Na}$ Presidência do Estado do Rio de Janeiro, Portela firmou contrato com esta Companhia, para a construção da Estrada de Ferro, que teria o mesmo nome da Companhia responsável por sua construção e administração.

A Estrada de Ferro Melhoramentos do Brasil era o resultado da concessão realizada pelo Governo do Estado àquela Companhia. Entre os grandes feitos atribuídos a Francisco Portela esteve conseguir um alinhamento de interesses entre o Governo Central (Deodoro da Fonseca), a Prefeitura do Município Neutro (Francisco Antonio Pessoa de Barros) e a Presidência do Estado do Rio de Janeiro, em torno do tema. A Companhia foi gestada como uma sociedade anônima, em meio à política econômica implantada pelo então Ministro da Fazenda, Rui Barbosa.

O Plano Econômico de Rui Barbosa pretendia modernizaro país a partirdo fomento a industrialização. Para ele, o crescimento econômico do país só poderia ser alcançado se fosse implementado a partir de capital próprio, e não à custa do endividamento com agencias financeiras internacionais. Seu foco principal estava na liberação de capitais, a partir da emissão de moeda nacional (ainda que sem lastro para tal).

Seu foco era estimular a formação de empresas. Com isso, Rui Barbosa previa que a circulação de capitais, obtidos à custa do surgimento e consolidação destas empresas garantiria a formação do lastro necessário à política econômica desencadeada. Em um primeiro instante, várias empresas aproveitaram esta oportunidade e conseguiram captar na bolsa de valores grandes somas de capitais. Este foi o caso da Companhia E. F. Melhoramentos do Brasil. Diferente do que acontecia a época do Império, esta Companhia não gozava de garantia de juros, pagos pelo Governo.

Entre os anos de 1890 e 1892 foram realizados os primeiros estudos de viabilidade técnica e financeira. Nesta ocasião, uma comissão técnica realizou visitas por vários pontos da Serra do Tinguá para a definição do melhor traçado. Entre os participantes da comissão, estavam Conrado Niemeyer e Paulo de Frontin. Ambos já conheciam bastante a região. Frontin havia realizado casamento com a filha do Barão de Javary.

Contudo, a forte especulação imobiliária e a formação de empresas fictícias provocaram a ruína deste modelo econômico. O país passou a conviver com alta na inflação e um elevado grau de endividamento interno. A catástrofe deste plano econômico colocou o país em uma forte crise, que ficou conhecida por Encilhamento. A Companhia E. F. Melhoramentos do Brasil conseguiu suplantar esta crise econômica e em 1893 deu início as obras da ferrovia.

Um primeiro trecho da Estrada de Ferro Melhoramentos do Brasil foi inaugurado em 01 de novembro de 1895 . O ponto de partida era próximo a Praça da Bandeira e ao rio Maracanã. A estação do lugar foi batizada pela Companhia com o nome Alfredo Maia. Neste caso, o nome da estação não pegou! A estação foi construída na base do lugar onde iniciou-se a formação da comunidade da Mangueira. Daí, a nomeação, tanto do lugar, quanto da Escola de Samba da comunidade: Estação Primeira de Mangueira.

Deste ponto, a estrada de ferro foi deslizada por uma parte bastante plana, passando pela região suburbana do Rio de Janeiro. Honório Gurgel estava distante da Estação Primeira em $17 \mathrm{~km}$. Nesta estação foi projetada, e construída uma linha de integração (ramal até Sapopemba) com a antiga Pedro II, que naquele instante já havia sido rebatizada por Central do Brasil.

A inauguração desta primeira etapa da obra, e seu funcionamento, deu-se em paralelo a continuidade dos trabalhos. De Honório Gurgel, a estrada seguia por localidades como Pavuna, atingindo a Baixada Fluminense em lugares como São João do Meriti, Belforoxo. A estrada foi direcionada até a estação denominada Amaral, já em terras pertencentes ao lugarejo de Belém (atual Japeri), onde foi construído novo ramal para integração com a Central do Brasil.

Ambas as Estradas (Central do Brasil e Melhoramentos do Brasil), tinham estação no lugarejo de Belém, embora, estas estações estivessem localizadas em pontos diferentes. De Belém, a antiga Pedro II seguia em direção ao povoado de Rodeio, e de lá, seguia até Barra do Piraí. Já a Estrada Melhoramentos do Brasil, de Belém, passava a seguir paralela ao Rio Santana, subindo a Serra do Tinguá, em direção ao grande planalto situado à Serra do Couto.

O projeto técnico foi assinado por Paulo de Frontin. A estrada projetada diferia da antiga Estrada de Ferro D. Pedro II, que foi construída em bitola larga. Já a Melhoramentos do Brasil foi planejada para ser edificada em bitola estreita, o que diminuía muito os custos da obra. Outra diferença importante, no que se refere aos recursos técnico-científicos empregados se relaciona com a estratégia sobre como ultrapassar a Serra do Mar. 


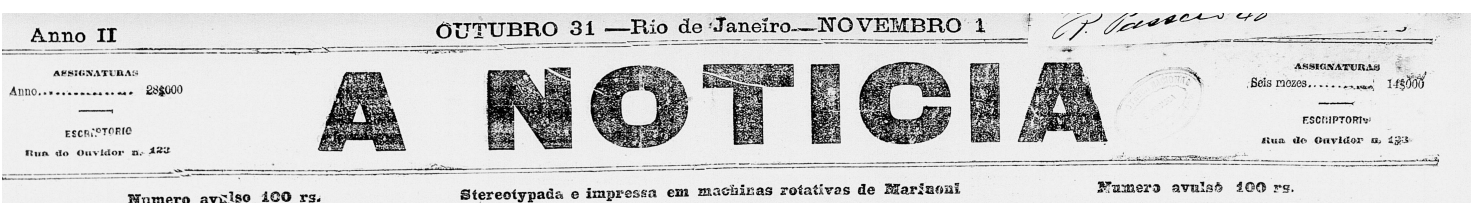

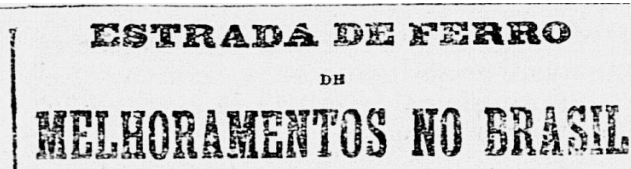

INAUGURAGÃO DA LIHHA DE SUBUREIOS

Inaugura-so amanhã ao meio-dia na estarão da Mangueira o primeiro trecho da 1 a seccão desta. íuturosa via-feries que vai ser peias zonas percorridas e pelo estado agudo da crise de transportes um grande escoadouro da montacáco exportacão das norcadorias para os $\mathrm{E}_{3}$ tados do Rio, Minas Geraes, não fatlando ro papol impor tante que nodesenvolvimento material do Districto Federal ella vai representar.

A concessão desta estrada do ferro foi tiia pelo Governo Provisorio ao ensenheiro Dr. João Candido Murtinho por decreto n. $436 A$ de 4 de jul'o do 1s91, sendo transterida á Empreza Ir. dustrial do Melhoramentos no Rrasil por decreto $n$. 619 de 24 de outubro do 1821 , sendo por fim approvados os estudos deinitivos de Mangueira, a Belem por decreio n. 1174 de 17 de dezenbro de 1852.

O ponto inicial d'esta estracia é actuamentena estacio da Nangueira, junto a Central do Birasil, de cija zona se afasta de 2 até 3 kilometros, percoirendo a linha desuburbios, a tinha principal ate o kiiometro 17 (parada Honorio Gurgel) e dahi u'ima só tangento

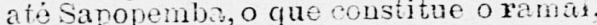
porque da parada honorio Gurgel a linha principal scoue até Beicm, pout termival da primeira seccĩo cujos trabalhos se acham bem adiantados do morlo a suppòr-se poder ser in a igrirala ainda este anno.

No intervailc de Mangueire e Sapopemba se encontram as duas estacö́s inicial e terminal de Manguoira o Sapopemba e as paradas seguintes: Silva Souza, Jockey-Club, Heredia de Sá, Dr. Vieira Fazenda, Cesario Machado, Encenheiro Del Castillo, Zieze, Cintra vidal, Terra Nova, Conselheiro Thomaz Coelho, Engenhei io Leal, Aranio, Coronel Magalnães, Inharajo (palavra composta de Inhauma e Ir.já) e Honorio Gnrgel. As duas estacões são de madeira pintada o telha franceza; as paradas cobertas de ferro galvani a lo.

O descavolvimento total da linha cuja bitola ede 1 metro entre trilhos de cerca de 20 kilometros e 30 metros, sendo que desse desenvolvimento pouco mais ou menos $80 \%$ em tangentes $\theta$ as curvas sempre de raio superior a 100 metres e declive maximo de $1 \%$, no mesmo em pecuenos trechos.

Além de alouns trabalhos technicos
Alem de alguns trabalhos technicos dignos de mencão, encontram-se $\div$ pontes de 10 metros cada uma sobre os rios Jacaré, Faria, Sapé e o Mugguenguè.

No seu tracado a estrada serve os poroados da Praia Pequeno, Car̃o do Bispo, Pilares, Engenho do Niatto, Alto de Cascadura, Morlureira, Sapé e Sapcpomba.

Pelo que acima expuzemos vê-se a importancia que n'um futuro não remoto vai ter esta via ferrea no systewa. de viacão do Districto Federal, já sørvindo a uina grande zona suburbana que эstả longe da central, já desenvolvendo os nucleos agricolas de pequena lavoura que embryonariamente se estão formando $\theta$ que têm encontrado na falta de transportes, nos fretes $\theta$ nas baldeacčes os maiores empecilhos para a vinda dos seus productos ao centro consumidor

de prineir oriem como é está capital. N'esse sentido ella vem prestar un re- s levante servico.

Ao illustrado Dr. Paulo Frontine a a homens do sua tempera $A$ Notacia ño regatearb́n nunca copplausos, applausos de $z$ que é merecedor pelo sen ardor,pola sua $\mathrm{g}$ encreia, pelo sou trabalho, pela suald actividade 3 pelo seu patriotismo.

Os estuks foram feitos sob a immediata inspeccão do dr. Paulo Frontin, o sendo coadjuvado pelo seu pesson techni- a co composto dos drs. Thoophilo a'Almeida, Del Castillo, Floresta de Miranda, b Mariano de Gliveira, Magzo do Carva- s lho, Prospcro A riani, eo dr. Theophilo a Cunha que infel zmente falleceis victi- d mado por molestia adquirida en sér- I vico.

0 engenheiro fiscal do governo a o $\mathrm{Si}^{2}$. Ir. João Fernandes da Silva, quo T substibaik o fallecido engenheiro ir. J. c Lea, com cujo nome a mp aza deno. milicu uma das suas paradas en home-? nagern a sua memoris.

Tol empreiteiro goral Ja construceão o distincto engenhairo D.". Alfredo Ma- I gno de Carvilino.

o trafe mo inangurado serádirigido i pelo Li. Foresta do Miranda caia t competencia é conhecida. 


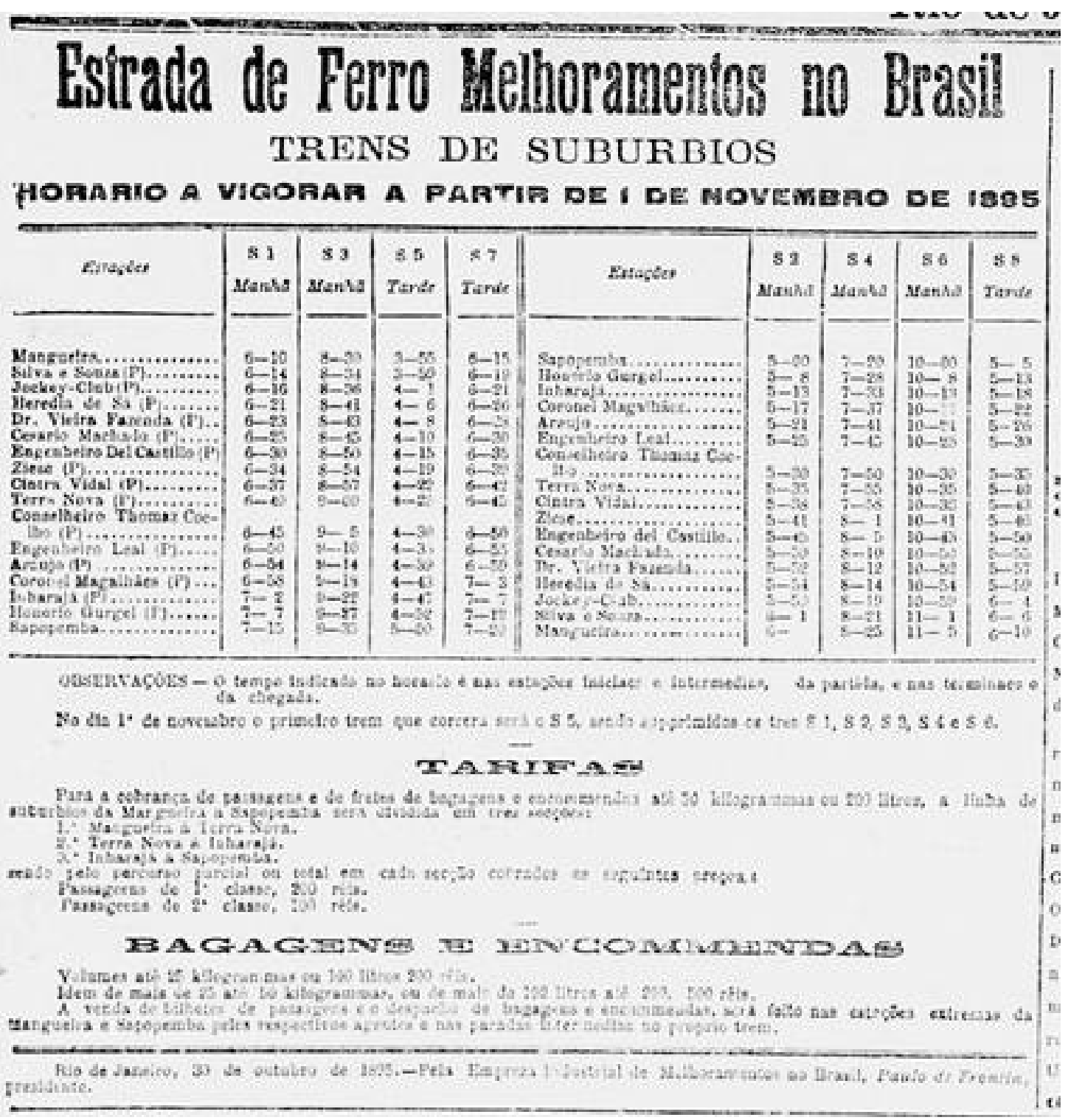

Fonte: Jornal A Notícia, de 31 de novembro de 1895. Páginas 1 e 4. Disponível em:

http://memoria.bn.br/DocReader/DocReader.aspx?bib=830380\&pesq=Estrada\%20de\%20Ferro\%20Melhoramentos $\% 20 \mathrm{do} \% 20$ Brasil\&pasta $=$ ano $\% 20189$ 


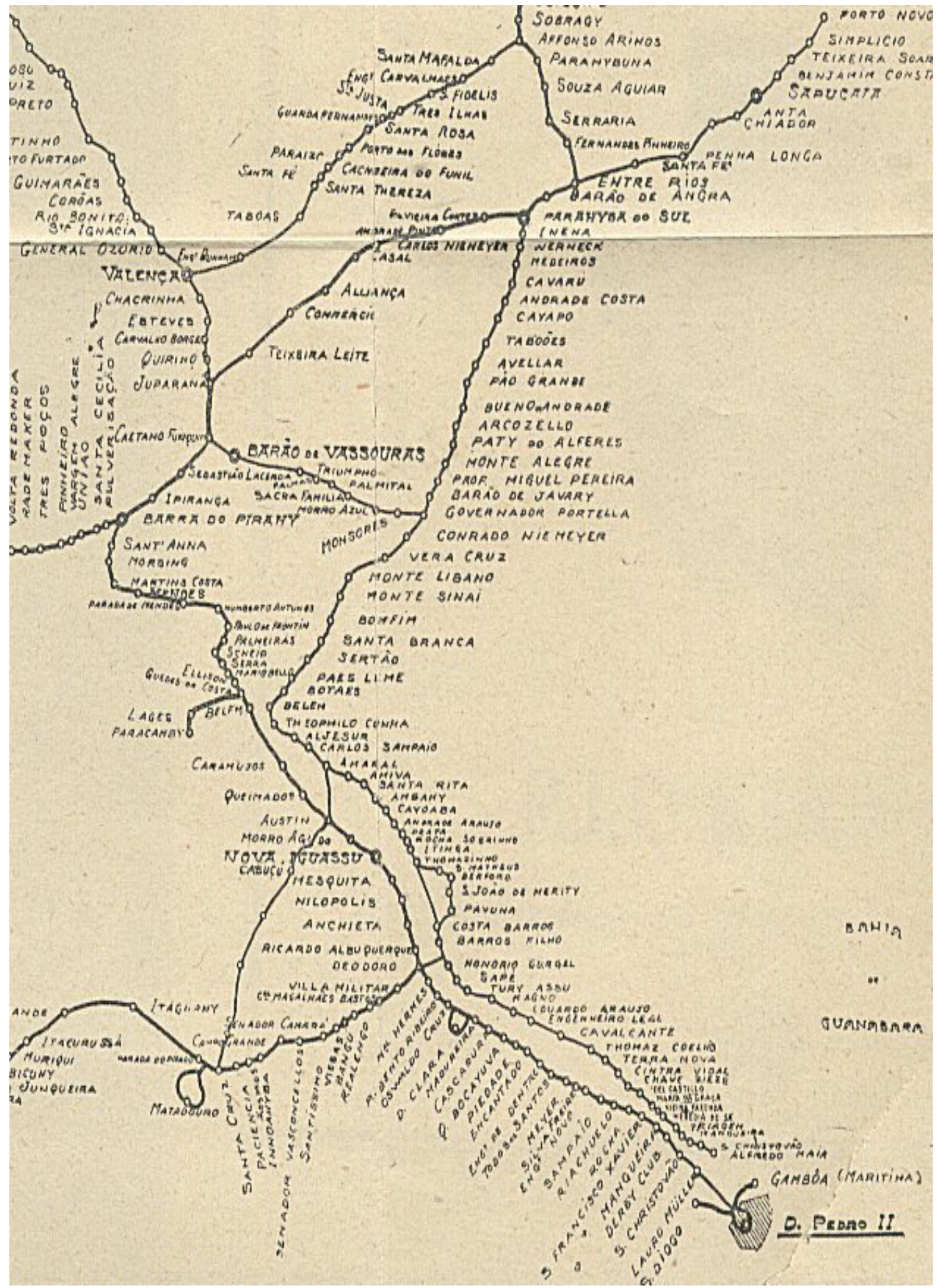

Descrição: Mapa da Linha do Centro e da Linha Auxiliar, da EFCB, em 1928, do livro Vias Brasileiras de Comunicação A Estrada de Ferro Central do Brasil, de Max Vasconcellos. No mapa, a Linha do Centro está no eixo Dom Pedro II-Belém-Barra do Pirai-Juparanã-Paraiba do Sul-Entre Rios-Sobragi, sendo que o restante aparecerá já no Estado de Minas Gerais. Por sua vez, a Linha Auxiliar corre sempre ao seu lado direito, aparecendo no eixo Alfredo MaiaBelém-Governador Portela-Paraiba do Sul-Porto.

Fonte: http://www.estacoesferroviarias.com.br/efcb_rj_linha_centro/mapa_linhacentro_rj.htm 
No que se refere a Pedro II, o trecho de subida da Serra do Mar foi edificado entre os anos de 1858 e 1865. Para a transposição da Serra foram construídas colossais artes de engenharia, como pontes, aterros e túneis. Entre as grandes obras, ocupou papel de destaque a construção de 13 túneis - sendo que um deles, o de número 12, que ligava os povoados de Rodeio e Mendes, foi considerado como a maior obra de engenharia de toda a América Latina.

Já toda a extensão da Estrada de Ferro Melhoramentos do Brasil, foi construída entre os anos de 1893 e 1898.

$\mathrm{Na}$ visita de reconhecimento logístico à região previamente mapeada, Frontin, Bicalho, Vieira Souto e Hargreaves sensatamente optaram por usar as estradas de terra recémabertas pelos caboclos da Serra para acessar de forma mais prática e rápida as encostas menos íngremes das colinas, em cujos flancos menos acidentados poderiam ser cravados os trilhos da ferrovia desejada sem maiores contratempos. Com tal decisão, determinaram eles que o leito da estrada de ferro precisava acompanhar as águas do Santana de forma ininterrupta, já que o rio de fato configurava um referencial geográfico perfeito para área. Essa escolha explica o fato de os trilhos que partem de Japery escoltarem criteriosamente o Santana até a localidade de Vera Cruz, somente aí abandonando suas margens para desbravar as montanhas em direção a Fragoso e Portela (...). Afiguravase para os diretores, engenheiros e projetistas da época um problema considerável à primeira vista insolúvel: como vencer a profunda garganta criada pela Natureza logo após a estação, em cujo seio corriam as águas perenes do rio? Como vencer o instigante problema técnico oferecido pelo Vale do Santana e levantar na áspera garganta da Serra impiedosa uma ponte metálica com particularidades absolutamente inéditas e até então não experimentadas, cuja engenharia era ainda praticamente desconhecida no país? ${ }^{8}$

A única grande arte de engenharia foi o Viaduto Paulo de Frontin, localizado sobre o Rio Santana, montado em 1897. Segundo nos informa o professor Sebastião Deister à elaboração do projeto desta "imensa ponte de ferro que deveria ser ali construída" não poderia ser em linha reta, mas em curva, "em virtude da topografia peculiar do local". 9 Ainda segundo o professor Sebastião Deister, para a elaboração do projeto, os engenheiros da Companhia começaram a desenvolver nos gabinetes da empresa ferroviária

profundos estudos para a criação de um portentoso viaduto, cujo leito apresentasse uma curvatura adequada a implantação dos trilhos e a ordenação sequencial dos dormentes, um coeficiente de inclinação apropriado aos balanços dos vagões e um índice de tração suficientes para suportar o peso e as oscilações de comboios compostos por pesadas locomotivas e dezenas de vagões repletos de carga e passageiros (...) algumas imposições físicas não podiam ser ignorados em hipótese alguma: a força dos ventos vindos do Sudoeste, cuja velocidade e força talvez comprometessem a estrutura superior da obra (...) o impacto das águas do rio em suas bases, especialmente quando de suas assustadoras cheias de verão, e o material formador da estrutura metálica, cuja qualidade garantisse a perenidade da obra. Tendo enviado para a Bélgica os croquis do viaduto, memoriais descritivos (...) plantas da área de Vera Cruz, dados físicos e matemáticos relativos a curvaturas (...) com exata e detalhada definição do que sonhavam erguer na Serra, os engenheiros responsáveis (...) conseguiram planificar as minúcias de uma obra memorável. (...) Podemos considerar a construção do Viaduto de Vera Cruz como o mais extraordinário e elogiável feito. ${ }^{10}$

Projetado no Brasil, pelo corpo de Engenheiros da Companhia Estrada de Ferro Melhoramentos do Brasil, o viaduto foi construído na Bélgica. Seus módulos foram levados até Vera Cruz e sua montagem ocorreu ao longo do ano de 1897.

Segundo o professor Sebastião Deister, A Estrada de Ferro Melhoramentos do Brasil foi dividida em três seções básicas: $1^{\text {a }}$ Mangueira (Alfredo Maia - Rio de Janeiro) a Sertão (Conrado) com o total de $85 \mathrm{~km} ; 2^{\mathrm{a}}-$ Sertão a Governador Portela com o total de $25 \mathrm{~km} ; 3^{\mathrm{a}}$ - Portela a Paraíba do Sul com o total de $55 \mathrm{~km}$.

Ainda em 1897 foi aberta a circulação mais algumas estações localizadas na Baixada Fluminense. No dia 29 de março de 1898, foram inauguradas todas as demais estações e abria-se toda a extensão da Estrada de Ferro Melhoramentos do Brasil ao tráfego.

\section{Governador Portela}

Como verificamos anteriormente, muitas pessoas tiveram papel importante na construção da Estrada de Ferro Melhoramentos do Brasil. Uma de suas principais artes de arquitetura, o Viaduto localizado sobre o Rio Santana e montado em 1897, homenageou o engenheiro Paulo de Frontin. ${ }^{11}$

Alfredo Maia foi um dos empreiteiros que trabalhou na construção da Estrada de Ferro Melhoramentos do Brasil. Em sua homenagem foi batizada a primeira estação da Ferrovia. Contudo, a Estação foi montada em local onde já havia todo uma comunidade. E por isso, apesar da homenagem, o nome pelo qual a Estação passou a ser conhecida foi Estação Primeira de Mangueira. São vários os exemplos em que poderíamos demosntrar algumas das relações referentes a toponímea das Estações da Estrada de Ferro.

Como vimos acima, o primeiro presidente constitucional do Estado do Rio de Janeiro desengavetou o projeto de construção da Estrada de Ferro que deveria subir a Serra do Mar, em sua fração conhecida como Serra do Couto. Foi por meio de seu empenho que teve início a formação da Companhia Estrada de Ferro Melhoramentos do Brasil, que recebeu a tarefa de construir esta estrada. Foi ainda, por seu esforço, que Barra do Piraí (principal entroncamento ferreo da América Latina daquele tempo) foi transformada em, 
Município (o primeiro do período Repúblicano). Para Francisco Portela, a modernização do Estado do Rio de Janeiro passava pelos trilhos. Era através de um sistema de transporte ágil e barato, que se poderia irradiar o desenvolvimento econômico para diversos pontos do Estado.

Um dos maiores desafios técnicos empreendidos pelos engenheiros da Companhia era fazer que as locomotivas atingissem o planalto da Serra do Couto. Para termos uma ideia deste desafio, vale lembrar que Belém estava a apenas 30 metros acima do nível do Mar. Para atingir a estação de Paes Leme, deveria percorrer a distância de 11, $041 \mathrm{~km}$ e chegar a 49 metros de altitude. De Paes Leme até Conrado, percorreria apenas 8, 011 $\mathrm{km}$ e atingiria 61 metros de altitude. De Conrado até Arcádia, percoreria uma distância ainda menor, apenas 5,
$919 \mathrm{~km}$, mas atingiria 155 metros de altitude. Chegavase a um dos pontos mais ingremes da Serra. De Arcádia para Vera Cruz, percorria-se uma distância de $9,729 \mathrm{~km}$. Ao atingir Vera Cruz, chegava-se a 398 metros acima do nível do Mar. De Vera Cruz até Francisco Fragoso, percorria-se apenas 7, $222 \mathrm{Km}$ para atingir 516 metros de altitude. $\mathrm{O}$ último ponto para se atingir o planalto da Serra do Couto, representava também uma vitória da técnica, da ciência e da tecnologia sobre a natureza. A primeira Estação deste Planalto teve seu nome em homengem a Francisco Portela. De Francisco Fragoso até Governador Portela percorria-se apenas 2. $084 \mathrm{~km}$ e chegava-se ao ponto de maior altitude da Ferrovia. A Estação Governador Portela estava a 634 metros acima do nível do Mar. Antes da Estação, era mero ponto de passagem.

Gráfico 1. Distância entre as estações na Serra do Tinguá

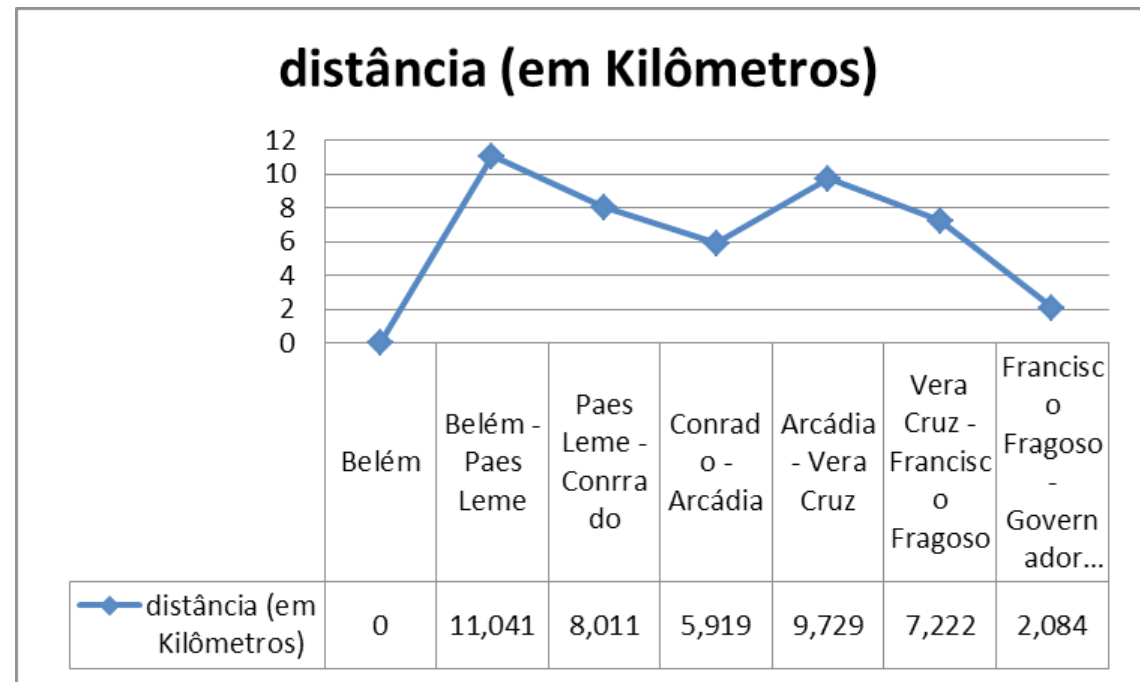

Fonte. DEISTER, S. Pelos Trilhos do tempo. In: DEISTER, S. Serra do Tinguá - 300 anos de conquistas: do século XVII ao século XX. Volume IV - Pelos Trilhos do tempo. Dedalus $1^{\text {a }}$ ed.: Rio de Janeiro, 2003, página 02

Gráfico 2. Altitude em relação ao nível do mar, das estações na Serra do Tinguá

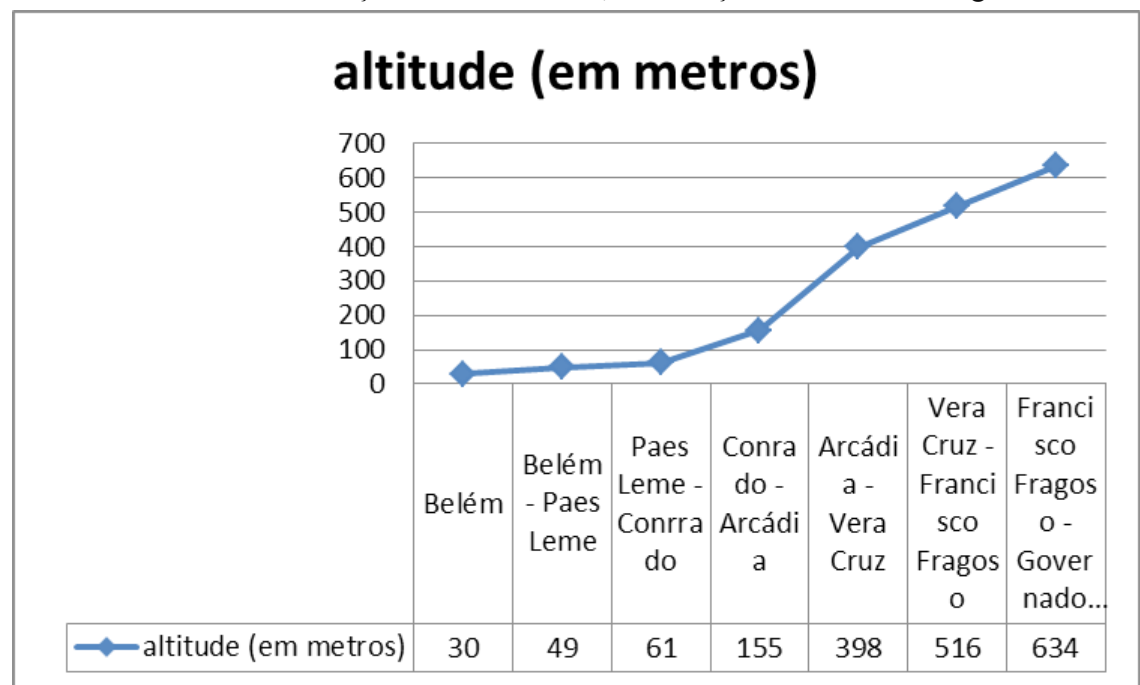

Fonte. DEISTER, S. Pelos Trilhos do tempo. In: DEISTER, S. Serra do Tinguá - $\mathbf{3 0 0}$ anos de conquistas: do século XVII ao século XX. Volume IV - Pelos Trilhos do tempo. Dedalus $1^{\text {a }}$ ed.: Rio de Janeiro, 2003, página 03. 
A implantação da Estação de Governador Portela deu origem a um povoado que, em poucos instantes foi transformado em um dos centros mais dinâmicos da Região. Com efeito, Governador Portela teve na ferrovia o principal mote de seu crescimento econômico e social. A estação de Governador Portela foi inaugurada em 29 de Março de 1898. O fator decisivo a sua área, como sendo o principal ponto de apoio da Estrada de Ferro Melhoramentos do Brasil estava associado também aos aspectos topográficos. Era alí que se iniciava o amplo planalto da Serra do Couto. Isso favoreceu que alí se implantasse a oficina de mecânica que permitiria avaliar e reparar (caso necessário) as condições técnicas das locomotivas e dos vagões após a subida da Serra.

Era alí que se verificava a pressão das caldeiras das locomotivas, lubrificavase suas engrenagens abastecia com água e lenha e oferecia aos passageiros uma parada de descanso após as sinuosas curvas da Serra. Agrande extensão do planalto favoreceu a construção de oficinas, depósitos de mecânica, garagens cobertas onde se abrigavam vagões, guindastes, locomotivas e também pátios com vasta malha de manobras. Ainda criouse ao seu redor o horto florestal onde se plantavam os eucaliptos destinados aos postes e dormentes da via férrea.

Em 2 de julho de 1903 a Estrada de Ferro Melhoramentos do Brasil foi repassada a Central do Brasil e convertida em Linha Auxiliar. Em 1914 foi construído o ramal Jacutinga. Este ramal ligava a Linha Auxiliar a Minas Gerais. Passando por Vassouras e com ponto de conexão com a Central do Brasil em Barão de Juparanã, o ramal Jacutinga atingia o local chamado Santa Rita de Jacutinga, já no Estado de Minas Gerais. O entroncamento deste Ramal, na Linha Auxiliar, era a Estação (e o povoado que se formou ao seu redor) de Governador Portela.

Tais medidas propiciaram a Governador Portela uma substantiva fase de crescimento. Havia todo um movimento crescente de comércio, passageiros, funcionários que nos entervalos de trabalhos se viam enfadigados ao trabalho árduo, necessitavam de horas de lazer e descanso. Por volta de 1914, uma fração do terreno ao lado da Estação foi transformado em um campo de futebol, ampliando-se os espaços de sociabilidade no lugar. Por volta de 1925 foi iniciada a construção de residências para os agentes da estação, para os engenheiros, e também para os operários que serviam as ferrovias.

Vendas, bares, farmácias, quitandas, sempre com características assobradadas (embaixo o negócio comercial em cima a residência) foram edificadas. Tudo planejado detalhadamente: os funcionários não precisavam se afastar da localidade, havia uma espécie de "controle", sobre suas vidas.

As constuções das casas apresentava característica semelhantes umas as outras com inconfundível estilo. As casas simples destinadas aos operários eram sempre contíguas. As mais espaçosas e luxuosas aos engenheiros e os mestres de linha. A ocupação dessas casas eram feitas por contratos entre os funcionários e a empresa onde constava um termo de permissão de uso destes imóveis onde era outorgada na presença de testemunhas com cláusulas e condições que substanciavamse ao fórum da comarca de Juiz de Fora (MG).

Com efeito, Governador Portela teve na ferrovia seu crescimento sendo seu ponto de referência com um núcleo de profissionais com alta capacidade, tanto que ali se fizeram grandes musicos regionais que criaram para seu lazer a sociedade musical XV de Novembro,onde reunidos na praça aos domingos levavam a alegria aos moradores que se dividiam entre a música e o futebol. ${ }^{12}$

Com o depósito de máquinas a sua manutenção, os carros de transporte, a conservação das linhas férreas mais tarde já em 1940, foi construída a Escola Profissional de nível ginasial, que preparava os jovens para funções técnicas especializadas. As novas necessidades de ensino começavam a ganhar corpo em Governador Portela. As séries regulares dos então chamados cursos primários não se mostravam mais suficientes para atender a multiplicação de alunos e a constante demanda de mão de obra especializada que impunha o crescimento das cidades. Em pouco tempo a rede ferroviária descobriuse muito carente de funcionários e técnicos que pudessem exercer alguns serviços fundamentais ao longo da movimentada Linha Auxiliar. Ao longo dos anos o Centro De Formação Profissional (CFP) foi melhorando suas instalações e aprimorando sua área didática, aplicando conteúdos que correspondiam ao ensino fundamental e a parte prática onde se aprendia os ofícios de: metalurgia, tornearia, ajustagem, marcenaria.

$\mathrm{O}$ ingresso ao CFP era feito por meio de processo seletivo com aplicação de prova escrita e teste psicológico. Sendo assim tornouse uma espécie de tradição os ferroviários incentivavam seus filhos a ingressarem no CFP e posteriormente seguir carreira dentro da ferrovia. ${ }^{13}$

Enfim, a criação da escola profissional trouxe inúmeros benefícios à Governador Portela desde capacitação profissional até mesmo na parte recreativa. A vila de Governador Portela teve um desenvolvimento acelerado após a emancipação política do município de Miguel Pereira e enquanto a direção da ferrovia esteve sob a orientação e chefia da Estrada de Ferro Central Do Brasil que adotava a política ferroviária como serviço público. Com a transferência da estrada de ferro Central Do Brasil para estrada de ferro Leopoldina, Governador Portela sofreu um baque em sua economia

12 BARREIROS, V. José Antônio da Silva (José Nabo): Camaradas. Edição do autor, Rio de Janeiro, 1963. Páginas 59-60.

13 MUNIZ, M. V. Subsídios à História do Município de Miguel Pereira. Rio de Janeiro: Estab. Gráficos Borsoi S. A., 1982. Página 53. 
adotando uma nova política ferroviária, dando preferência ao transporte de cargas e desativando os trens de passageiros. Com estes acontecimentos vários funcionários foram transferidos para outros locais. Depois passou a pertencer a ferrovia a Rede Ferroviária Federal Sociedade Anônima (RFFSA), superintendência a Campos dos Goitacazes SR8, e as numerosas casas vendidas para seus operários. ${ }^{14}$

\section{Conclusões preliminares}

Ao longo de nossos estudos verificamos que desde a segunda metade do século XIX foi implementado um projeto civilizatório que articulava desenvolvimento econômico e social com a abertura de ferrovias. Mesmo com a bertura da crise imperial, este projeto não foi abandonado. Pelo contrário, desde a implantação da primeira ferrovia no Brasil, o esforço pela abertura de estradas de ferro só fez crescer. Contudo, a abertura da crise imperial deu-se em paralelo a retração econômica da Cultura Cafeeira no Interior da Província do Rio de Janeiro. Talvez por isso, os esforços em criar novas linhas ferroviárias, além da ampliação da Estrada de Ferro D. Pedro II foi parcialmente interrompidos.

Com o Início da República, o Presidênde da Província do Rio de Janeiro, Francisco Portela, retomou projetos anteriores e estilulou a formação da Companhia Estrada de Ferro Melhoramentos do Brasil como estratégia para o desenvolvimento econômico e social do Estado.

Uma das iniciativas mais importantes, neste sentido, foi a construção da Estrada de Ferro Melhoramentos do Brasil. Com seus 176, $300 \mathrm{~km}$, esta estrada de ferro propiciou a formação de diversas estações que foram ponto para a interiorização do desenvolvimento econômico do Estado. Nas áreas de entorno de várias destas estações foram formados muitos povoados.

Entre estes povoados, destacamos o de Governador Portela. Situado no planalto da Serra do Couto, vivenciou o rápido desenvolvimento econômico e social. No entorno da estação foram construídas as oficinas, escolas e casas que impulsionaram o comércio local.

\section{Referências}

BARREIROS, V. José Antônio da Silva (José Nabo): Camaradas. Edição do autor, Rio de Janeiro, 1963.

DEISTER, S. Pelos Trilhos do tempo. In: DEISTER, S. Serra do Tinguá300 anos de conquistas: do século XVII ao século XX. Volume IV - Pelos Trilhos do tempo. Dedalus $1^{\text {a }}$ ed.: Rio de Janeiro, 2003.

MARINHO, Pedro Eduardo Mesquita de Monteiro. Companhia Estrada de Ferro D. Pedro II: a grande escola prática da nascente Engenharia Civil no Brasil oitocentista.Topoi (Rio de Janeiro), v. 16, n. 30, 2015.
MUNIZ, M. V. Subsídios à História do Município de Miguel Pereira. Rio de Janeiro: Estab. Gráficos Borsoi S. A. , 1982.

RODRIGUES, Hélio Suêvo. A formação das estradas de ferro no Rio de Janeiro: o resgate da sua memória. Memória do Trem, 2004, páginas 1214. 